
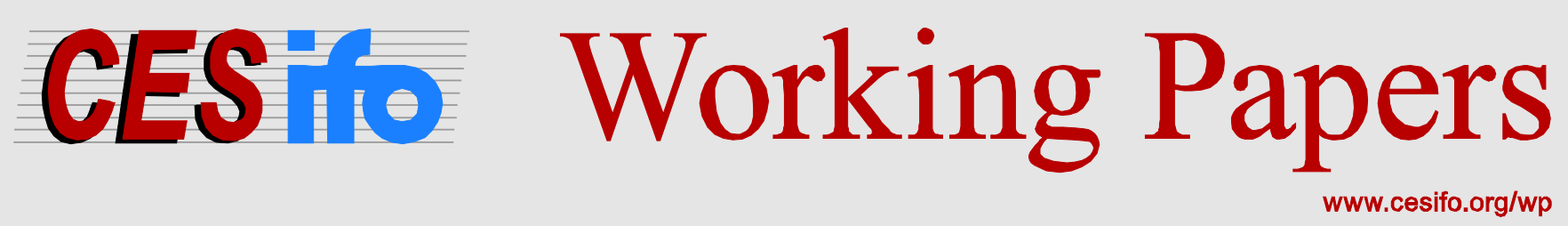

\title{
Petchey's (2015) Extension of Oates \& Schwab's (1988) Efficiency Result Revisited
}

\author{
Thomas Eichner \\ Rüdiger Pethig
}

CESIFO WORKING PAPER NO. 6315

CATEgORY 1: PUBLIC FinANCE

JANUARY 2017

An electronic version of the paper may be downloaded

- from the SSRN website:

- from the RePEc website:

- from the CESifo website: WwW.SSRN.com

www.RePEc.org

www.CESifo-group.org/wp 


\title{
Petchey's (2015) Extension of Oates \& Schwab’s (1988) Efficiency Result Revisited
}

\begin{abstract}
Oates and Schwab (1988) consider an economy with mobil capital and jurisdictions that suffer from local pollution. They show that welfare-maximizing jurisdictions implement the first-best, if they take prices as given and have at their disposal a capital tax and an environmental standard. Petchey (2015) claims that the efficiency result of Oates and Schwab can be extended to a large price-influencing jurisdiction. In the present note we show that the concept of Pareto efficiency cannot be applied in Petchey's model. Next, we expand his model by a second jurisdiction and prove that Petchey's claim is false, i.e. we show that the allocation implemented by a large price-influencing jurisdiction that sets an environmental standard and a capital tax fails to be (Pareto) efficient.
\end{abstract}

JEL-Codes: H230, H710.

Keywords: pollution, environmental standards, mobile capital, taxes.

Thomas Eichner Department of Economics

University of Hagen

Universitätsstr. 41

Germany - 58097 Hagen

thomas.eichner@fernuni-hagen.de
Rüdiger Pethig

Department of Economics

University of Siegen

Hölderlinstr. 3

Germany - 57068 Siegen

pethig@vwl.wiwi.uni-siegen.de 


\section{Introduction}

Petchey (2015) extends the model of Oates and Schwab (1988) by relaxing the assumption that jurisdictions are small price-takers and claims to show that the important efficiency result of Oates and Schwab can be preserved by a welfare-maximizing large jurisdiction. The small price-taking jurisdictions attain efficiency in the basic model of Oates and Schwab, because they do not tax mobile capital, although they could do so. In sharp contrast, Petchey claims to have shown that in his model of a large non-price taking economy, positive capital tax rates are necessary for 'first-best efficiency'. This note disproves Petchey's (2015, p. 466) result that "... relaxing the price-taking small-country assumption does not lead to an inefficient outcome and the Oates and Schwab result still holds."

Petchey's benchmark is the model of Oates and Schwab who consider an economy with many jurisdictions that are endowed with capital and produce a consumption good by means of capital and productive waste emissions. The jurisdictions' representative consumers derive utility from the consumption good and suffer from pollution generated by local waste emissions. Capital and the consumption good are traded among the jurisdictions. Each jurisdiction has two policy instruments at its disposal, a tax on capital and an environmental standard. The key result of Oates and Schwab is that an efficient allocation is attained through decentralized policy making when the jurisdictions take the rate of return to capital as given and maximize their jurisdiction's welfare, i.e their consumers' utility. The jurisdictions then set efficient environmental standards and find it in their interest to abstain from taxing capital.

In order to assess Petchey's claim we begin with briefly describing his analytical framework and find that the standard concept of Pareto efficiency cannot be applied, simply because his model contains a single representative consumer only. In order to allow for a correct efficiency comparison with Oates and Schwab, we then expand Petchey's setup by adding a second jurisdiction in a very simple way while preserving all components of his original model. In the remaining part of the paper, we scrutinize the resultant two-jurisdiction model with respect to its efficiency properties, when a jurisdiction does or does not influence the net capital return via taxation, and compare the results with the efficiency result of Oates and Schwab. Our analysis reveals that the allocation of the economy with the price-influencing jurisdiction is characterized by the efficient allocation rule for emissions, but the allocation rule for capital is distorted. The jurisdiction makes use of its policy to manipulate the net return to capital in its favor which renders the allocation inefficient. When the large price-influencing jurisdiction maximizes welfare and the production function exhibits decreasing returns to scale investments in the jurisdiction are inefficiently low and 
emissions may be inefficiently high or low. When the jurisdiction maximizes income as in Petchey both investments and emissions are inefficiently low.

\section{Petchey's model}

Petchey focuses on a single jurisdiction that produces output $y$ of good $Y$ by means of mobile capital $k$ and waste emissions $g$ according to the production function

$$
y=F(k, g) \quad \text { with } \quad F_{k}>0, F_{g} \geq 0, F_{k k}, F_{g g}<0 .
$$

He justifies his single-jurisdiction setup by the conjecture that his results can be derived for a single jurisdiction or a multi-jurisdiction framework, and he chooses the single-jurisdiction case to present the idea most clearly. The supply of capital to the jurisdiction,

$$
k_{s}=S\left(\frac{r}{\omega}\right) \quad \text { with } \quad S^{\prime} \geq 0 \text { and } \omega>0 \text { and const. }
$$

comes from the international capital market.

As in the Oates and Schwab model, the representative consumer of the jurisdiction has a utility function of the type $u=\tilde{U}(x, g)$ with $\tilde{U}_{x}>0$ and $\tilde{U}_{g} \leq 0$, where $x$ is consumption of good $Y$. To ease the exposition, we will employ the simplified version of the function $\tilde{U}$,

$$
u=U(x)-\delta g \quad \text { with } \quad U_{x}>0 \quad \text { and } \quad \delta \geq 0
$$

where the parameter $\delta$ describes the constant disutility per unit of emissions. Petchey argues that his results hold for utility maximization with either $\delta>0$ and $\delta=0$. He analyzes the case $\delta=0$ because he considers the results more transparent. ${ }^{1}$ In contrast, we will focus on the case of pollution emissions $(\delta>0)$ and will comment on the special case $\delta=0$ later.

\section{Pareto efficiency and Oates and Schwab's result}

The structure of Petchey's model differs markedly from that of the Oates and Schwab model. The most consequential divergences are Petchey's single jurisdictions framework and the assumption not made by Oates and Schwab that there is an economic interdependence between the jurisdiction(s) and the 'rest of the world' in the form of the capital supply (2). Petchey $(2015$, p. 463) refers to $\omega$ in (2) as "some given rate of return determined in the

\footnotetext{
${ }^{1}$ If $\delta=0$, maximizing utility (3) is equivalent to maximizing consumption of the consumption good. Since the consumer spends all of its income on that good, utility maximization is equivalent to income maximization.
} 
world capital market". However, since neither that market nor any country in the 'rest of the world' is analytically specified with production, consumption and utility, the link between a parameter $\omega$ and some world market rate of return merely is an interpretation without explicit modeling and (micro)foundation in the formal analytical framework. ${ }^{2}$

In the Oates and Schwab model the concept of efficiency is the standard Pareto efficiency that is attained if it is not possible to improve a consumer's utility (or a jurisdiction's or country's welfare) without reducing another consumer's utility (or another jurisdiction's or country's welfare). Obviously, Petchey cannot apply that criterion in his model because there is only a single representative consumer. Therefore, his efficiency comparison with the Oates and Schwab result lacks a sound basis.

Result 1. Petchey (2015) fails to provide an extension to large open countries of the efficiency result of Oates and Schwab.

The observation that Petchey's comparison is flawed gives rise to the question how one can make a correct comparison. We find it both necessary and interesting to compare the Oates and Schwab efficiency result and the result in a model that allows to apply the Pareto criterion and preserves as much as possible of Petchey's (2015) analytical framework. To construct such a model, we leave Petchey's single jurisdiction as it stands and call it Home, for convenience, but expand his model by a simple structure of production and consumption in the 'rest of the world', which we call Foreign hereafter. We endow Foreign with the capital endowment $\bar{k}$ and the production function

$$
y^{\mathcal{F}}=F^{\mathcal{F}}\left(k^{\mathcal{F}}\right) \text { with } \quad F_{k}^{\mathcal{F}}>0, F_{k k}^{\mathcal{F}}<0,
$$

where the amount $y^{\mathcal{F}}$ of good $Y$ is produced by means of the capital $k^{\mathcal{F}}{ }^{3}$ It is easy to see that a capital supply function of type (2) follows from combining (4) with the first-order condition $F_{k}^{\mathcal{F}}\left(k^{\mathcal{F}}\right)=r$ that maximizes profits $\pi^{\mathcal{F}}=F^{\mathcal{F}}\left(k^{\mathcal{F}}\right)-r k^{\mathcal{F}}$ for given prices, and the capital resource constraint

$$
\bar{k}-k-k^{\mathcal{F}} \geq 0
$$

\footnotetext{
${ }^{2}$ Petchey's (2015, p. 466) classification of the closed/partially open/fully open economy depending on the derivative $S^{\prime}$ of (2) would be analytically relevant only if the 'rest of the world' would have been rigorously modeled. If Petchey's classification should mean to point to capital market imperfections other than through taxation, the comparison with the Oates and Schwab model would be meaningless.

${ }^{3}$ We refrain from modelling emissions and local pollution in Foreign which would not alter the results. The intention is to choose the simplest possible structure to support our objective while sticking as closely as possible to Petchey's original setup.
} 
Foreign exports the capital $k_{s}=\bar{k}-k^{\mathcal{F}}$ to Home that pays for the import with good $Y$. The pertinent resource constraint of good $Y$ then is

$$
y-y^{\mathcal{F}}-x-x^{\mathcal{F}} \geq 0
$$

where $x^{\mathcal{F}}$ is the consumption of good $Y$ of the representative consumer in Foreign whose utility is

$$
u^{\mathcal{F}}=U^{\mathcal{F}}\left(x^{\mathcal{F}}\right) \quad \text { with } \quad U_{x}^{\mathcal{F}}>0
$$

and whose income is the profit of Foreign's output producing firm $\pi^{\mathcal{F}}$ plus the capital income $r \bar{k}$.

In order to determine the Pareto-efficient allocation in this two-jurisdiction economy we maximize (3) subject to (1), (4), (5), (6) and $U^{\mathcal{F}}\left(x^{\mathcal{F}}\right) \geq \bar{u}^{\mathcal{F}}$, where $\bar{u}^{\mathcal{F}}$ is some (feasible) constant level of utility of Foreign's representative consumer. The solution of the associated Lagrangean

$\mathcal{L}=U(x)-\delta g+\lambda_{u}\left[U^{\mathcal{F}}\left(x^{\mathcal{F}}\right)-\bar{u}^{\mathcal{F}}\right]+\lambda_{y}\left[F(k, g)+F^{\mathcal{F}}\left(k^{\mathcal{F}}\right)-x-x^{\mathcal{F}}\right]+\lambda_{k}\left[\bar{k}-k-k^{\mathcal{F}}\right]$

is characterized by ${ }^{4} U_{x}=\lambda_{u}^{*} U_{x}^{\mathcal{F}}=\lambda_{y}^{*}, \lambda_{y}^{*} F_{k}=\lambda_{y}^{*} F_{k}^{\mathcal{F}}=\lambda_{k}^{*}$ and $\lambda_{y}^{*} F_{g}=\delta$. Applying the standard procedure of 'decentralization by prices', we make the assignments $p_{y}^{*}=\lambda_{y}^{*} \equiv 1$ and $r^{*}=\lambda_{k}^{*}$ and readily reach the following conclusions.

(I) In the no-policy case, the efficient allocation can be implemented as a general competitive equilibrium of the economies of Home and Foreign if and only if $\delta=0 .^{5}$ This is so because in the absence of policy the price-taking profit-maximizing firm in Home increases the emissions until $F_{g}=0$.

(II) If $\delta>0$, Home can restore efficiency if it abstains from taxing capital and sets the environmental standard $g=g^{*}$ that is implicitly defined by

$$
F_{k}\left(k^{*}, g^{*}\right)=r^{*} \quad \text { and } \quad F_{g}\left(k^{*}, g^{*}\right)=\delta \quad \text { with } \quad r^{*}=\lambda_{k}^{*} .
$$

While Scenario (II) assumes that Home does not levy a tax on capital, the question Oates and Schwab raised and answered is whether it is in the interest of welfare-maximizing jurisdictions to levy a capital tax on their firms if they take the rate of return to capital as given. To answer that question in our simple model, observe that with capital taxation the profit of Home's firm is $\pi=F(k, g)-(r+t) k$. Profit maximization yields the first-order

\footnotetext{
${ }^{4}$ The efficient allocation, prices and shadow prices are marked by an asterisk.

${ }^{5}$ Depending on the choice of $\bar{u}^{\mathcal{F}}$, the competitive solution needs to be complemented by a suitable lumpsum transfer from or to Foreign.
} 
condition $F_{k}(k, g)=r+t$ that implies a capital demand function, say $k=D(r+t ; g)$. Home's government maximizes utility $u=U\{F[D(r+t ; g), g]-r D(r+t ; g)\}-\delta g$ with respect to $g$ and $t$ taking the rate of return, $r$, as given. The first-order conditions $U_{x} \cdot\left(F_{k} D_{r+t}-r D_{r+t}\right)=$ 0 and $U_{x} \cdot F_{g}-\delta=0$ yield (8).

Result 2 (Oates and Schwab 1988). In our extended Petchey model, the allocation is Pareto efficient, if Home takes the rate of return to capital as given and chooses the environmental standard and the capital tax rate so as to maximize (domestic) welfare. Home sets the tax rate on capital exactly equal to zero.

\section{The large open economy and Petchey's result}

Next, consider the competitive economy, in which Home sets an environmental standard and taxes capital taking into account how its policy parameters $t$ and $g$ influence the capital market equilibrium. We will refer to this two-instrument policy as strategic policy as opposed to the non-strategic policy characterized in Result 2. To get informative results we assume that the production function $F$ from $(1)$ is homogeneous of degree $b \in] 0,1[$, i.e. that it satisfies $^{6}$

$$
y=F(k, g)=g^{b} F\left(\frac{k}{g}, 1\right)=: g^{b} H(z) \quad \text { with } \quad z:=\frac{k}{g},
$$

and that the utility function of $(3)$ is linear, formally $U(x) \equiv x$. Home's firm takes the environmental standard $g$ as given and maximizes profits $\pi=g^{b} H(k / g)-(r+t) k$ with respect to $k$. That yields the first-order condition

$$
F_{k}=g^{b-1} H^{\prime}(z)=r+t
$$

Home acts strategically in the sense that it takes into account its influence on the equilibrium rate of return on capital with its choice of $g$ and $t$. To specify that influence, we differentiate (2), (10) and the equilibrium condition of the capital market, $k=k_{s}$, and $\operatorname{get}^{7}$

$$
\begin{aligned}
\frac{\partial k}{\partial t} & =-\frac{S^{\prime}}{1-F_{k k} S^{\prime}}=-\frac{S^{\prime}}{1-g^{b-2} H^{\prime \prime} S^{\prime}}, \\
\frac{\partial k}{\partial g} & =\frac{F_{k g} S^{\prime}}{1-F_{k k} S^{\prime}}=-\frac{g^{b-2}\left[(1-b) H^{\prime}+z H^{\prime \prime}\right] S^{\prime}}{1-g^{b-2} H^{\prime \prime} S^{\prime}}, \\
\frac{\partial r}{\partial q} & =\frac{1}{S^{\prime}} \frac{\partial k}{\partial q} \quad \text { for } \quad q=t, g .
\end{aligned}
$$

\footnotetext{
${ }^{6}$ We refrain from reducing analytical complexity by assuming $b=1$, because with linear homogeneity the country's maximum income and consumption would be zero in the case $\delta=0$. Additionally, the results for $b \in] 0,1[$ are richer than the results for $b=1$.

${ }^{7}$ Following Petchey $(2015)$ we set $\omega=1$. Observe that $F_{k k}=g^{b-2} H^{\prime \prime}$ and $F_{k g}=-g^{b-2}\left[(1-b) H^{\prime}+z H^{\prime \prime}\right]$.
} 
Since Home's consumer spends all of her income $F(k, g)-r k$ on the consumption of good $Y$, her utility is $u=U[F(k, g)-r k]-\delta g$. The first-order conditions of maximizing that utility with respect to $t$ and $g$ under consideration of (11a)-(11c) are $^{8}$

$$
\begin{aligned}
& \frac{\partial u}{\partial t}=\left(F_{k}-r\right) \frac{\partial k}{\partial t}-\frac{\partial r}{\partial t} k=0 \quad \Longleftrightarrow \quad t=\frac{k \frac{\partial r}{\partial t}}{\frac{\partial k}{\partial t}} \\
& \frac{\partial u}{\partial g}=\left(F_{k}-r\right) \frac{\partial k}{\partial g}-\frac{\partial r}{\partial g} k+F_{g}-\delta=0 \quad \Longleftrightarrow \quad F_{g}=\delta .
\end{aligned}
$$

From (11c) and (12a) follows that the utility-maximizing capital tax is ${ }^{9} t=k / S^{\prime}$. It is interesting to observe that although changes in the environmental standard $g$ influence the capital market equilibrium, as (11a)-(11c) demonstrate, these changes do not distort the efficient allocation rule for emissions, as can be seen from (12b). When Home maximizes the utility and makes strategic use of its policy instruments $g$ and $t$ the allocation rule for emissions, (12b), is the same as the efficient allocation rule in (8). However, the allocation rule for capital in (12a) differs from the efficient rule in (8). The conclusion therefore is the

Result 3. When Home maximizes domestic welfare with strategic use of its policy instruments $g$ and $t$, the allocation of the two-jurisdiction economy is inefficient, in general, because the allocation rule for capital differs from the efficient rule.

We summarize our preceding analysis as follows. The condition (12b) is a necessary equilibrium condition whether Home acts strategically or not. Solving $F_{g}=g^{b-1}[b H(z)-$ $\left.z H^{\prime}(z)\right]=\delta$ from $(12 \mathrm{~b})$ for $k$ yields

$$
k=\left(\frac{z^{b-1} \delta}{b H(z)-z H^{\prime}(z)}\right)^{\frac{1}{b-1}}=: A(z) .
$$

The second pair of necessary equilibrium conditions derived from $F_{k}=r+t, F_{k}=r^{*}$ and $F_{g}=\delta$ is

$$
\frac{F_{k}}{F_{g}}=\frac{H^{\prime}(z)}{b H(z)-z H^{\prime}(z)}=\frac{r+k / S^{\prime}}{\delta} \text { and } \frac{F_{k}}{F_{g}}=\frac{H^{\prime}(z)}{b H(z)-z H^{\prime}(z)}=\frac{r}{\delta},
$$

where the first [second] equation relates to Home' strategic [non-strategic] action. To be able to solve these equations for $k$, we introduce the simplified version

$$
k_{s}=S(r)=2 r \quad \text { with } \quad S^{\prime}=2
$$

of the capital-supply function (2). ${ }^{10}$ Consideration of (15) in (14) gives

$$
k=B(z) \quad \text { and } \quad k=\frac{B(z)}{2} \quad \text { with } \quad B(z):=\frac{2 \delta H^{\prime}(z)}{b H(z)-z H^{\prime}(z)},
$$

\footnotetext{
${ }^{8}\left(F_{k}-r\right) \frac{\partial k}{\partial g}-\frac{\partial r}{\partial g} k=t \frac{\partial k}{\partial g}-\frac{\partial r}{\partial g} k=0$ follows from (11c) and (12a).

${ }^{9}$ That tax rate is exactly the same as the tax rate derived by Petchey (2015).

${ }^{10}(15)$ follows from setting $\bar{k}=2$ and specifying the production function as $F^{\mathcal{F}}\left(k^{\mathcal{F}}\right)=k^{\mathcal{F}}-\frac{\left(k^{\mathcal{F}}\right)^{2}}{4}$, the first-order condition of maximizing profits $F_{k}^{\mathcal{F}}=1-\frac{k^{\mathcal{F}}}{2}=r$ and $k_{s}=\bar{k}-k^{\mathcal{F}}$.
} 


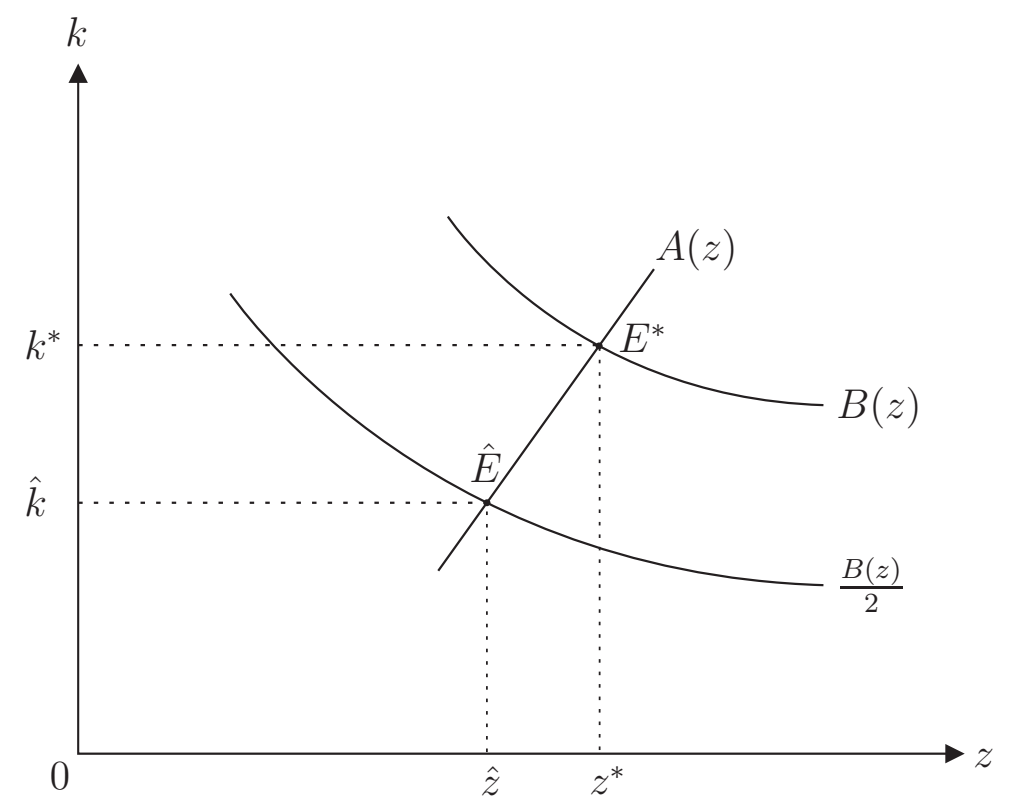

Figure 1: Equilibrium inputs with strategic and non-strategic policies

where $k=B(z)[k=B(z) / 2]$ is required to hold in the case of non-strategic [strategic] action. We show in the Appendix that $A_{z}>0$, if $F_{g g}<-z F_{g k}$ (which is a mild restriction we assume to hold), and $B_{z}<0$. Clearly, the equations $A(z)=B(z)$ and $A(z)=B(z) / 2$ define the equilibrium values of capital and emissions when Home acts non-strategically and strategically, respectively.

Figure 1 conveniently illustrates the results. With strategic action, the capital input $\hat{k}$ and the capital-emissions ratio $\hat{z}$ (point $\hat{E}$ in Figure 1 ) are smaller than the corresponding variables $k^{*}$ and $z^{*}$ (point $E^{*}$ in Figure 1 ) in the efficient equilibrium without strategic action. The environmental standards $g^{*}$ and $\hat{g}$ also differ, in general, but the difference $g^{*}-\hat{g}$ may attain either sign. From $\hat{k}<k^{*}$ and $\hat{k}<\left(k^{*} / g^{*}\right) \hat{g}$ follows $\hat{k}<\min \left[k^{*},\left(k^{*} / g^{*}\right) \hat{g}\right]$ and hence $\hat{g}>g^{*}$, if $k^{*}<\left(k^{*} / g^{*}\right) \hat{g}$, and $\hat{g}<g^{*}$, if $k^{*}>\left(k^{*} / g^{*}\right) \hat{g}$.

Result 4. In our two-jurisdiction model, Home's strategic action leads to inefficiently low capital input and to emissions that may be too high or too low.

The important message of Result 4 is that it is not true, in general, that since the allocation rule for emissions, $F_{g}=\delta$, is efficient in case of strategic action, the environmental standard must be at its efficient level $g^{*}$. The economic interpretation of Result 4 is straightforward. Home's strategic action is an indirect way for Home to influence in its favor the unit price and quantity of capital imports. Home makes use of its policy instruments to exert market power in an indirect way. The maximum welfare of Home is greater with than without exerting market power, because when Home acts strategically it does not choose the tax rate $t=0$, although it has the option to do so. 
To understand how Home makes use of its market power it is convenient to consider the special case in Figure 1 in which the $A(z)$ curve happens to be vertical $\left(F_{g g}+z F_{g k}=0\right)$. Then the capital-emissions ratio $z$ remains unchanged when moving from non-strategic to strategic action, and with strategic action both capital input and emissions are smaller than without. The welfare-reducing effect of this move is less output of good $Y$ due to reduced input of both productive factors. The welfare-enhancing effects are less pollution and a capital import bill $\hat{r} \hat{k}$ that is lower than in case of non-strategic action due to both the smaller quantity $\hat{k}$ and the lower per-unit price $\hat{r}$. The effect of the smaller import bill is that the income and consumption of Home's consumer declines less than the output of good $Y$. Reducing the import bill via strategic action is therefore welfare enhancing.

As mentioned above, Petchey analyzes the case that the pollution parameter is zero $(\delta=0)$. Since we focused on $\delta>0$, a comment on Petchey's special case is in order. If $\delta=0$, utility maximization is equivalent to income maximization in our and Petchey's model, and Home's income as well as the profit of Home's firm can be costlessly increased as long as $F_{g}>0$. It is therefore necessary to introduce some upper bound on the productivity of emissions. Following Pethig (1976) we assume that there is $z=\bar{z}>0$ such that

$$
F_{g}(k, g)=g^{b-1}\left[b H(z)-z H^{\prime}(z)\right] \gtreqless 0 \quad \Longleftrightarrow \quad z \gtreqless \bar{z}
$$

(17) implies that $z=\bar{z}$ is a necessary condition for the maximization of both Home's income and profits. Consequently, Home may let its firm choose the profit-maximizing emissions and pursue its goal of utility maximization by means of strategic taxation only. With $z=\bar{z}$ and $k=\bar{z} g(10)$ turns into

$$
F_{k}=a k^{b-1}=r+t \quad \text { with } \quad a:=\frac{b H(\bar{z})}{\bar{z}^{b}} .
$$

The three equations (2), (18) and $k=k_{s}$ determine the capital market equilibrium for predetermined tax rates $t$ and the effects of taxation on $r$ and $k$ are

$$
\frac{\partial k}{\partial t}=-\frac{S^{\prime}}{1-F_{k k} S^{\prime}}=-\frac{S^{\prime}}{1+a(1-b) k^{b-2} S^{\prime}} \quad \text { and } \quad \frac{\partial r}{\partial t}=\frac{1}{S^{\prime}} \frac{\partial k}{\partial t} .
$$

Home's government maximizes $U\left[(a / b) k^{b}-r k\right]$ with respect to $t$. Combined with $k=k_{s}$, (15) and (19), this yields $a \hat{k}^{b-1}=\hat{k}$ with strategic taxation and $a\left(k^{*}\right)^{b-1}=k^{*} / 2$ with non-strategic taxation such that

$$
\hat{k}=a^{\frac{1}{2-b}} \quad \text { and } \quad k^{*}=(2 a)^{\frac{1}{2-b}}
$$

are the equilibrium levels of capital in case of strategic and non-strategic taxation, respectively. From (20) readily follows $\hat{k}<k^{*}$ as in the case $\delta>0$ discussed above. Since $z=\bar{z}$ holds with and without strategic taxation, we find that $\hat{g}<g^{*}$. 
Result 5. Petchey's (2015, p.465) main result reads: "A large open economy that is not a price-taker chooses first-best efficient environmental standards if it can tax mobile capital and chooses this tax optimally". This theorem is not true, when efficiency is defined as Pareto efficiency.

We have already observed in the context of Result 4 that one cannot conclude, as Petchey apparently does, from the observation that the allocation rule is efficient $\left(F_{g}=0\right)$ that the environmental standard is also efficient in case of strategic action. Moreover, it is also incorrect to infer from the alleged efficiency of the environmental standard in case of strategic action, as Petchey apparently does, that the entire allocation is efficient and that hence "... the Oates and Schwab first-best result holds" (p. 461). A necessary condition for Pareto efficiency is a perfectly competitive capital market. If capital is taxed at the source, the efficient allocation rule $F_{k}=r$ for capital is distorted $\left(F_{k}=r+t\right)$ whether or not the allocation rule for emissions $\left(F_{g}=0\right)$ is the efficient one.

\section{Concluding remarks}

This note has revisited the efficiency of a large open economy that taxes capital and sets an environmental standard to influence the net return to capital. To make a correct efficiency comparison we augment Petchey's model by a second jurisdiction. It is shown that Petchey's claims that a large open economy chooses the efficient environmental standard and that Oates and Schwab's efficiency result still holds are false. Another important issue - neither dealt with by Petchey nor in this paper - is to juxtapose the outcome of the Oates and Schwab model to that of a model of 'large' jurisdictions all of which tax capital, set an environmental standard, and seek to influence the rate of return to capital in their favor.

\section{References}

Oates, W.E. and R.M. Schwab (1988): Economic competition among jurisdictions: Efficiency enhancing or distortion inducing?, Journal of Public Economics 35, 333-354.

Petchey, J. (2015): Environmental standards in a large open economy, Journal of Public Economic Theory 17, 461-467.

Pethig, R. (1976): Pollution, welfare, and environmental policy in the theory of comparative advantage, Journal of Environmental Economics and Management 2, 160-169. 


\section{Appendix}

Sign of the derivative of the functions $A$ and $B$ from (13) and (16)

(13) is the solution of $F_{g}-\delta=0$. Total differentiation of $F_{g}-\delta=0$ and $g=k / z$ yields

$$
F_{g k} \mathrm{~d} k+F_{g g} \mathrm{~d} g=0 \quad \text { and } \quad \mathrm{d} g=\frac{1}{z}(\mathrm{~d} k-z \mathrm{~d} z) .
$$

Hence $z F_{g k} \mathrm{~d} k+F_{g g} \mathrm{~d} k-z F_{g g} \mathrm{~d} z=0$ and $\frac{\mathrm{d} k}{\mathrm{~d} z}=\frac{z F_{g g}}{z F_{g k}+F_{g g}}$ which is positive if and only if $F_{g g}<-z F_{g k}$.

We write the functions in (16) as $k=c \frac{F_{k}}{F_{g}}=\frac{c}{\frac{F_{g}}{F_{k}}}$ with $c=\delta$ or $c=2 \delta$

$$
\frac{\mathrm{d} k}{\mathrm{~d} z}=-c\left(\frac{F_{g}}{F_{k}}\right)^{-2} \cdot \frac{\mathrm{d}\left(\frac{F_{g}}{F_{k}}\right)}{\mathrm{d} z}=-c\left(\frac{F_{g}}{F_{k}}\right)^{-2} \cdot \frac{F_{g}}{\sigma z F_{k}}=-\frac{k}{\sigma z}<0,
$$

where

$$
\sigma:=\frac{\mathrm{d} z}{\mathrm{~d}\left(\frac{F_{g}}{F_{k}}\right)} \cdot \frac{F_{k}}{z F_{g}}=-\frac{H^{\prime}\left(b H-z H^{\prime}\right)}{\left[(1-b) H^{\prime 2}+b H H^{\prime \prime}\right] z}
$$

is the positive elasticity of substitution. 